\title{
Finding Common Ground: Community Arts Festivals as Spaces for Placemaking
}

Authors Tristi Brownett (a) and Owen Evans (b)

a) School of Allied and Public Health Professions, Faculty of Health and Wellbeing, Canterbury Christ Church University, Canterbury, Kent, UK, CT1 1PU email: tristi.brownett@canterbury.ac.uk

b) Department of Media, Edge Hill University, Ormskirk, Lancashire, UK, L39 4QP email: evanso@edgehill.ac.uk

Corresponding Author: Tristi Brownett

\begin{abstract}
The present research posits the significant role that arts and cultural festivals play in contributing to placemaking and generating well-being within communities. Placemaking is recognized to be important when considering how to improve population health and wellbeing, and festivals can be seen to amplify those benefits. Drawing on qualitative data gathered from interviews with festival organizers in SouthEast England and deploying theories of space from Foucault and Massey, the present article argues that community arts and cultural festivals support the positive creation or transformation of pro-social spaces that could support community acceptance and well-being, the ability to live together and cohesively and accepting difference.
\end{abstract}

\section{Highlights}

- The study identified four key themes demonstrating that through their use of space, arts and cultural festivals contribute to community sense of well-being and place.

- Festivals can imbue connection to and sense of belonging to place for local communities through history, heritage and the traditions presented.

- The study suggests access to and participation in the arts is enhanced by using everyday and familiar places.

- How festivals reimagine and use space is important to community development and potentially to a placemaking agenda for enhancing public health.

- This paper conceptualizes the complex interrelationships of spatial theories specifically applied to arts and culture festivals for placemaking. 


\section{Keywords}

Arts festivals; placemaking; community well-being; heterotopia; community assets 


\title{
Finding Common Ground: The Conception of Community Arts Festivals as Spaces for Placemaking.
}

\begin{abstract}
The present research posits the significant role that arts and cultural festivals play in contributing to placemaking and generating well-being within communities. Placemaking is recognized to be important when considering how to improve population health and wellbeing, and festivals can be seen to amplify those benefits. Drawing on qualitative data gathered from interviews with festival organizers in south-east England and deploying theories of space from Foucault and Massey, the present article posits that community arts and cultural festivals can support the positive creation or transformation of pro-social spaces that could support community acceptance and well-being, the ability to live together and cohesively and accepting difference.
\end{abstract}

\section{Highlights}

- Four themes show arts festivals may contribute to contribute to well-being and place.

- Community festivals seek to instill a connection and sense of belonging to place.

- Access and participation in the arts may be enhanced by using everyday places.

- How festivals reimagine and use space may develop community and enhance public health.

- The paper explores interrelationships of spatial theories of festivals and placemaking.

\section{Keywords}

Arts festivals; placemaking; community well-being; heterotopia; community assets

\section{Introduction}

There is a plethora of festival research undertaken from an economic, tourism and business perspective. However, there is a smaller body of research which seeks to understand the human impacts, for example: experience (Biaett, 2019); social capital building (Arcodia and Whitford 2006); sense of place (Derrett, 2003) social phenomena (Duffy and Mair 2018; Quinn, 2019); quality of life (Jepson and Stadler, 2017); and volunteer networks (Jarman, 
2018). However, the contribution of urban arts and cultural festivals to health and well-being is under-researched. This article describes the findings of a small qualitative study that interviewed festival organizers. This study seeks to engage with, and embed, the findings in a theoretical discourse that spans academic disciplines, fostering a discussion about the contribution of festivals and their deployment of space and place to support health and wellbeing. Thus, the paper proposes a thesis setting out a body of research that will require additional investigation with festival attendees and volunteers to evaluate the true benefits of these community events and the ways in which they are conceived, designed and realized. What we propose here is a theoretical model upon which a more detailed evaluation of the festival experience could be based.

For the purposes of this paper, health is described in its broadest and most holistic sense rather than the absence of disease, and recognized to be influenced by external factors, alongside personal beliefs and sense of mentally being well. Here, well-being is described as being eudaimonic. That is, that there is an individual and personal sense of human fulfilment and growth leading to a state of flourishing, influenced very much by the context of individual and communal life (Ryff and Burton, 2006).

Placemaking has become a popular concept in discussions that link community studies with arts and culture, as well as health and well-being. Whilst subject to varying definitions, particularly relating to town planning, placemaking broadly relates to the assets within a community, the organization and accessibility of community spaces, and how these contribute to health and well-being (Corcoran and Marshall, 2015).

Place, and in particular its characteristics and design, shape how we live our lives and can influence behaviours of people that live in them (Heller and Adams, 2009). These physical and environmental characteristics include the opportunities to walk and cycle with access to green and public spaces (Koohsari et al., 2017), the access to affordable, healthy food, and the ready access to employment, goods and services (Jones and Yates, 2013). These complex environmental determinants can impact positively or negatively on human health (Bronfenbrenner, 1994). Therefore, the activity of placemaking is considered extremely important when considering how to improve population health and well-being.

It can therefore be seen that more than physical characteristics and services, placemaking is about the active creation of a prosocial environment. This is an environment that 
influences individuals and communities to behave cooperatively in ways that may benefit the health and well-being of others (Dovidio et al., 2012). Thus, to cooperate, communicate, share experiences, culture, memories and heritage (Corcoran and Marshall, 2015) could reduce social isolation and the number of groups leading parallel lives. This form of cooperation contributes to placemaking through the creation of active participation in civic decision-making and the opportunities for that to be shared equitably within a community (Alevizou et al., 2016; Locality, 2018). Placemaking should be a collective process (Blokland, 2009) and therefore, should be actively planned and organized with community, so that people do not have a sense that they are having ideas and initiatives imposed upon them from above or outside (Andrews, 2014). Platt and Knight (2018) argue that whilst grassroots festivals embedded in place can contribute to the placemaking process, it is not without tensions and challenges.

A number of relatively recent reports from a diverse array of bodies and organizations have focused on the importance that place can play in our everyday lives (e.g. British Academy, 2017a; Dyer, 2016; Local Government Association, 2017; Locality, 2018). Baroness Andrews' Culture and Poverty report for the Welsh Assembly Government in 2014 served to initiate public interest originally in Wales, but then further afield. She highlighted the importance of what the Welsh call cynefin (pronounced kin-ev-in), a difficult word to translate into English, but one which evokes the sense of local pride and belonging emanating from history and heritage within communities, as well as the memories and stories of those who live there. The British Academy's Where We Live Now report (2017b) highlights the ways in which 'places matter':

[Places] shape the way we live our lives, feel about ourselves and the relationships we have with others. Moreover, places - not least because of their history, character and physical form - contribute significantly to personal and societal well-being. [...] Most of us have immense affection for the places where we live: they might be places where we grew up, live or work now; where we have family and other relationships; and places are full of memories, stories and our lived experiences. (2017b, p, 1-2)

With its focus on spatially inspired well-being, the British Academy report chimes closely with the recent Creative Health report by the All-Party Parliamentary Group on Arts, Health and Wellbeing (APPGAHW), which underlines 'the power of space to be uplifting' by 'profoundly engag[ing] the senses of sight, touch and sound' (2017, p, 65). All of these 
different reports lay a common emphasis on the importance of a sense of place to health and well-being. However, to date, there is little focus on the way that particular spaces or sites might inspire a deepening of such well-being, a gap this article seeks to address. Taking as its focus arts and cultural festivals in the community, the study reported here examines the extent to which they can stimulate or contribute to well-being in this placemaking context from the ways in which they are conceived and designed spatially by the organizers, in an attempt to develop a sense of community cohesion and unlock healthpromoting assets within that community.

Drawing specifically on spatial theories of Michel Foucault and Doreen Massey, and underpinned by qualitative data drawn from a small study of eight community festival organizers in south-east England, we posit which characteristics of community festivals might be able to facilitate the development, and deepening, of cynefin. Furthermore, we suggest that community festivals might thereby contribute to a 'living legacy' (Brownett, 2018, p, 76) and the creation of an enduring community of cultural citizenship. The article explores the extent to which festivals of this kind might be regarded potentially as 'therapeutic landscapes' (Williams, cited in Cattell et al., 2008, p, 546), which are deemed to comprise 'natural and built environments; social environments; and symbolic environments' (Cattell et al 2008, p, 546). We contend that community-based arts festivals can be viewed as concrete and metaphorical focal points with the capacity to bring different individuals and groups together, to promote health and well-being, and foster social capital and community cohesion.

Theoretically, the important spatial role for festivals can be mapped through the work of Foucault (2008) and Massey (2005). In their different ways, their theories envisage space as having transformational potential. It is our contention that Foucault's concept of the 'heterotopia' can meaningfully be applied to the way local arts festivals can transform community space (Foucault, 2008). He perceived heterotopia as sites contiguous with everyday spaces; connected to, and yet apart from, those spaces. These spaces facilitate transformation through the activities that they engender. By changing our perception of familiar spaces, heterotopic sites thus have the ability to draw us out of ourselves and potentially generate a capacity for self-evaluation precisely by splintering the familiar. They help us, therefore, to see familiar things from a fresh perspective, potentially challenge our 
prejudices, and thus can change the way we view the world around us. ${ }^{1}$ Similarly, Massey's work on space explains how our perceptions of the world might also be transformed. She lays her particular emphasis on the way that space has the potential to bring us into contact with others, whom we might not otherwise encounter, and thereby to experience 'a collection of interwoven stories of which that place is made' (2005, p, 119), and thereby evoke a sense of cynefin, in other words. In For Space, Massey elucidates in her introduction the supposed distinction between space and place, before indicating that her study was inspired by a decision to resist the distinction, especially as 'place' was traditionally seen as meaningful and 'space' as somehow abstract and meaningless (2005, p, 6). So, for the purposes of this article and its specific focus, we use the two terms as synonyms, siding with Massey, whilst acknowledging their potentially different nuances and uses in other contexts. There is simply not sufficient scope in this article to engage with well-worn discussions about any semantic differences between the two terms, where our principal focus is necessarily on community festivals, placemaking and well-being.

By combining these two theoretical perceptions of the way space can be experienced and reimagined, and drawing on the interviews with festival organizers about the way they have conceived and designed their respective events, we argue that festivals have the potential to bring people together, and that these gatherings can positively influence our perceptions of the world around us. This contention chimes with evidence in Creative Health that reinforces how 'casual social contact at local level is central to building trust. Arts engagement, which often involves casual social contact at a local level, is regularly cited as a forum for building trust' (APPGAHW, 2017, p, 79).

In his work on interculturalism, Ted Cantle has highlighted, in particular, how certain groups lead parallel lives within communities that lack spaces where bridges can be built between disparate groups (Cantle, 2012). Such bridges are needed to generate opportunities for meaningful contact in order to reduce suspicion and prejudice. By encountering what Massey describes as the 'multiplicity of trajectories' $(2005, p, 63)$ that coexist in spaces, we are confronted constructively with the lives and stories of others. It is our contention, therefore, that community arts and cultural festivals have transformative potential, by adapting space, or our perception thereof, while at the same time creating an opportunity

\footnotetext{
${ }^{1}$ Peter Johnson's analysis of Foucault's inchoate concept of heterotopia has been very helpful in our own deployment of it in this present context. See Johnson (2006).
} 
for casual social contact and trust-building through cultural engagement. As such, it recalls Emile Durkheim's notion of 'collective effervescence' (Ehrenreich, 2007, p, 2). However, by bringing people together in this way community arts festivals not only contribute to developing stronger social bonds, but also have a unique potential to contribute to wellbeing, since 'social relations in a multiplicity of aspects will nurture good health and social care ecologies' (APPGAHW, 2017, p, 80). As such, festivals have a unique potential to link health and place.

The existing evidence base about community arts festivals is limited, tending to focus on the economic and tourism benefits of festivals, rather than the production of wellbeing and social connections, particularly in poorer areas. Following unexpected findings from a research study intended to investigate social capital for generating wellbeing ([name redacted], 2018), the paper responds to this lacuna. Specifically, we examine how community arts festivals deploy, and liberate access to, space and indicate the well-being benefits that can accrue as a result. Community arts and cultural festivals operating in everyday accessible places can, we argue, provide a basis for meaningful communal connection and contribute to collective wellbeing in communities. Further research will be needed to see if community arts and cultural festivals can indeed operate as the bridges Cantle identifies as necessary, and how inclusive they appear to be. However, from the data here we can see that the organizers conceive of their events as mechanisms to bring their diverse communities together, by seeking to unlock and use accessible public space in an attempt to make them as inclusive as possible. Our article therefore posits some of the ways in which we believe this organization of space might support the festivals' aspirations to create common ground.

\section{Methods}

The design of the earlier research ([Name Redacted], 2018) was intended as a small-scale prospective investigation into the social mechanisms of local community festivals. As such the approach was constructivist grounded theory, with the analysis being socially constructed (Charmaz, 2008), providing theoretical insights into how festival organizers reported that they embed their practice in their community.

Prior to this study, university ethical approval was obtained. One-to-one interviews with eight arts and culture festival organizers (hereafter referred to as interviewees) based in the southeast of England were undertaken. Laing and Mair (2015, p, 257 citing Szaryzc, 2009) 
indicate that a small number of participants for this type of study are typical. The participants for this study were identified via social networks and through snowball sampling. This strategy was chosen because the focus of the research was to find festivals that were seeking to engage a local audience, and were thus not always ticketed. Given the nature of these festivals, in the main they did not have a big marketing budget and were not advertising themselves outside of their locale.

Each arts festival offering, takes place in towns and small cities and is available free of charge or at low cost (see table 1). All of the coastal towns are areas recognized to be of high deprivation. In most cases, these areas were part of a wider arts regeneration initiative. Six of the eight interviewees, though assuming the role of festival organizer had come from an arts-making or artistic background. No financial incentive was offered to interviewees.

\begin{tabular}{|c|l|l|}
\hline Festival & Cultural Offering & Location \\
\hline P1 & Opera, Dance, Theatre, Community Arts & Coastal Town \\
\hline P2 & $\begin{array}{l}\text { Opera, Dance, Theatre, Community Arts, Parade, } \\
\text { Visual Arts }\end{array}$ & City \\
\hline P3 & $\begin{array}{l}\text { Parade, Community Arts, Street Theatre, } \\
\text { Community Production }\end{array}$ & Coastal Town \\
\hline P4 & Music & City \\
\hline P5 & Parade, Community Arts, Street Theatre & Coastal Town \\
\hline P6 & Music, Visual Arts & Coastal Town \\
\hline P7 & $\begin{array}{l}\text { Three interlinked festivals, Music, Dance, Theatre, } \\
\text { Community Arts, Visual Arts, Community } \\
\text { Production }\end{array}$ & Coastal Town \\
\hline P8 & Community Arts, Visual Arts & Coastal Town \\
\hline
\end{tabular}

Table 1. Festival Offering

The interviewer conducted semi-structured interviews lasting between 30-60 minutes. Open 
directive questions were asked around the themes of the type of festival offering, the intended audience, the aims of the festival, the unintended consequences of the festival, festival evaluation and whether the generation of well-being was an aspiration. The purpose of this interview approach was to enable participants to provide their own narrative and thick description (Geertz, 1983). The interviews took place in a venue of the interviewee's choice to facilitate their ease and candid contribution. A portable recording device was used to capture the interview, which was then transcribed verbatim. Interviewees were encouraged to indicate where commercially sensitive or confidential information had been revealed so that this could be redacted prior to analysis. An earlier pilot study had revealed this to be of utmost importance to festival organizers, as funding for arts festivals is highly competitive. All data was treated as confidential.

In order to identify major themes, the interview transcripts were re-read and audio recordings played to ensure familiarity with the data. A coding handbook and inductive open coding identified patterns of meaning and further descriptive codes were assigned. In sum, 17 codes were identified, later collated into four themes. Two coders agreed on the themes, using thematic analysis complementary to the chosen methodology, and grounded in a theory-driven approach (Braun and Clarke, 2006).

\section{Findings}

Below we discuss the four key findings of our thematic analysis which we named, Cynefin, Spaces for Participation, Spaces for Being Together and Spaces for Transformation. The discussion that follows illustrates how these themes are important in terms of the potential contribution of community arts and culture festivals to a sense of place and well-being. It is important to recognize that although we write about them as discrete themes, they are overlapping concepts, which will further be addressed in the ensuing discussion.

\section{Cynefin}

Throughout the interviews there was a strong articulation of cynefin, even if it was not described using this term. Respondents referred to a strong sense of place and belonging, interwoven with memories, stories, history and heritage within the community. The importance of history, heritage or the traditions of places were central to festival construction and imagination:

"[The festival was] connected with the dockyard [...] it was absolutely heaving with people [dressed as] sailors and ladies [...] dressed as whores going up to the men 
and saying 'round the back for a sixpence'. Everyone had such good fun [...] the old boys loved it, "cause they were sailors." [P5]

The importance of wanting to show off the geographical place to outsiders and celebrate its particular qualities was also a key motive.

"[...] the summer festival, was to do something that showed the best of the place and started to reveal what it has to offer [...]people outside have a low perception of the place. [...] that's a really powerful reason for us to do it. You have to be rooted in the place but the primary actual reason was to go, look at this amazing place."

The personal connection of belonging to a place and its community is argued to be one of the domains essential to good health and well-being (Atkinson et al., 2017). Furthermore, it is one of the key principles of the Healthy New Towns initiative (NHS England, 2018). However, Atkinson highlights that the common values, understandings of place and cultural heritage are essential for realizing community well-being and yet may prove exceedingly complex to evaluate empirically (Atkinson et al., 2017). The later discussion will go on to posit a model that we believe might function as an evaluation framework for ascertaining who comprises community festival audiences and what benefits they derive from participating.

Arts and cultural festivals seek to use of space to elicit cooperation, and collaboration is critical to the identity of the festival and the development of placemaking:

"and it comes back to the idea of what would happen if you break down the walls of the art centre and invite the community to help you programme the space." [P7]

Festival organizers interviewed reported that the location of their festival was often decided by the availability of low-cost or free local places. However, they reported that they specifically chose to celebrate the location, its heritage, and the stories and memories that permeate these places. Therefore, the use of community spaces naturally complements and amplifies this ethos, with the inherent 'potential to engender deeper knowledge of the community roots and the meaning of the landscapes to them' (Andrews 2014, p, 50).

\section{Participation}


As highlighted above festival organizers use community spaces for their events and report that they often liberate local spaces out of necessity. This is both a financial decision, but often also as a result of a lack of, or restricted access to, cultural assets and purpose-built venues. They indicated that the consequence of using local spaces and sites actually has the potential to increase participation and engagement with the arts, as Andrews has posited (2014), though further evidence will be needed to evaluate the success of this aspiration.

Distilled from the 'multiplicity of trajectories' described by Massey $(2005, p, 5)$, this theme describes both the spaces that allow people to bump into one another:

"[...] you start to get this blending between people who initially thought that wasn't for them and they didn't understand, [but] are now completely part of it. And that activity in that pub connects those people to lives, to the wider challenges that are happening all the time." (P7)

and extends to an intended development of a safe space to animate individual, and collective, participation.

"But the beautiful kind of hidden, or you know, the added value that was unexpected [...] that we'd engaged in such a kind of genuine family-oriented way; they all then felt so comfortable with us as a group that came into [the gallery] and they experienced a totally new cultural experience and engaged with people that they probably would never speak to. Because they were in this kind of safe environment that was actually facilitated by their children." (P8)

Atkinson has noted in her systematic review that there is evidence that events such as festivals generate neutral spaces for people to socialize, and in particular the use of natural spaces fosters active participation (Atkinson et al., 2017). However, whilst she provides no evidence for participation being a specific output of the chosen space, she acknowledges the sort of places that the festival organizers in our research sought out can be defined as 'community infrastructure', that is, 'public places and "bumping" places designed for people to meet, including streets, squares, parks, play areas, village halls and community centres' (Atkinson et al., 2017, p, 21). 


\section{Being Together}

In this theme festival organizers sought to create a momentary sense of community by purposely liberating the space for celebration in sites where that might not ordinarily happen such as the beach, community centre, church, harbour, water tower, empty shops or vacant buildings. The spaces used in this way are often already deemed communal or open, democratic spaces but not generally used for arts and cultural activities:

"One lady said, 'oh, I saw this amazing thing [...] there was this guy sitting in a chair, dressed as a polar bear telling stories'. It was us. We put a yurt outside Debenhams at one of the festivals [...] and she said my kids loved it, it's the best thing I have ever seen in my entire life." (P1)

This theme evidences that community events have the potential to facilitate improved social interactions (Bagnall et al., 2018). There is, however, always the danger that, albeit seeking to be inclusive, these festivals remain exclusive. In each case here, organizers stated that provision was made to try and create an event that was as open as possible and that everyday places were important in achieving that aim.

Cattell et al. (2008) describe the importance of the everyday places within a community for bringing people together to develop and maintain friendships, even in the most fleeting of encounters. In this way, quotidian settings comprise potential opportunities for escape, but are also essential in connecting people to the place where they live. The everyday spaces that the local community arts festivals interviewed here endeavour to liberate and reimagine, potentially allow such interactions to be fostered and strengthened, especially where people otherwise lead parallel lives or strong social bonds do not already exist. The findings of our own study appear to show that festival spaces are potentially important, therefore, for the contribution to, and the development of relationships with others through the casual contacts that arts and cultural gatherings can give rise to.

These festivals potentially provide space for human connection through shared cultural experiences, the transfer of personal memories and a sharing of stories, which ultimately celebrate the community and its heritage (Black, 2016). Story-telling and the sharing of cultural memory is recognized as essential to the ongoing development of community. This sharing underpins the notions of placemaking and cynefin. Stories and shared memories are the glue that connects people and potentially mobilizes neighbourhoods to act with 
collective interest (Russell, 2011). Furthermore, this story-telling and participation in festival events provides opportunities for communities to define, create and present their sense of collective self, and the place that they are from (Derrett, 2009). However, the question remains that more evidence is needed to demonstrate that local communities engage with the events and experience this benefit.

\section{Space for Transformation}

Using the concept of heterotopia, we suggest that the arts and cultural festivals at the heart of this research seek to reimagine everyday spaces, by using activities or events to create a permeability within what might ordinarily be considered a fixed and boundaried space with a set function, be it a beach, a shopping centre or a pub. This permeability enables the festival participant to safely step outside of their everyday self by entering the festivalgenerated heterotopia and engaging with the cultural experience. As an example, one of the festival organizers interviewed described an art installation by local adolescents, in a deprived coastal area, as a walk 'up the hill', "[...] which is how the kids would describe it going up the hill [...] to experience a bit more of the cultural value of the area." [P8]

Arts festivals also provide an opportunity for conversations about how the community are perceived or perceive themselves. Organizers talked about using small grants to fund consultative art works to help people get to know their local area, such as the walk described above, or to find out more about their local community, or how they felt about themselves: "[W]e did a consultative piece of work as an art installation, [...]Two words came out, [...] "apathy" and "dirty" from every respect [...]."(P1)

This research finding also describes how the festival seeks to creates an atmosphere that inspires conversations and facilitates transformation in the participants, for example, through active curation of an environment that festival participants and local contributors would find conducive to feeling relaxed or safe. However, we also noted that the described festival's use of space, combined with the specific cultural offering, appeared to stimulate a wider, more communal, transformation of how the community sees itself and the opportunities available: "the [cultural] landscape here is changing [...] I would say that our summer festival is driving that change" (P1). Here too further evaluation will be needed to 
ascertain the extent to which this potential is realized or felt by those participating, to underpin the anecdotal evidence of the organizers themselves.

\section{Discussion}

The four identified themes of our research - cynefin, spaces for participation, being together, and transformation - show that arts and cultural festivals in particular have the potential both support and demonstrate their essential role within the placemaking agenda, most especially when conceived and designed in such a way that accessible public space is used. The Halton Cultural Manifesto for Wellbeing (Halton NHS Commissioning Group, 2017) provides a good example of how the arts in general can support residents to imagine new kinds of connected communities; to develop their own strengths and abilities, so that they can live independent lives and develop health resources within the places they live. Based on the interviews with festival organizers and their observations about how they set up the festival space, our thesis is that community festivals might amplify these benefits.

Through the reimagining and repurposing of space, community festivals have huge potential to create new (or renewed) physical and emotional connections, which might lead to generating a sense of belonging by changing our perspectives. The heterotopic space thus established could be truly inclusive and intercultural, uniting Foucault and Massey's respective interpretations of space. A note of caution here, is that we acknowledge that there is not yet specific evidence of this in our findings, and additional evaluation will be need to assess who attends these festivals and what well-being benefits they might derive from them, and therefore whether the aspirations of the organizers are matched by the outcomes. Other authors note tensions brought about by loss of place (Friedmann, 2010) and commercial festivals (Jarman, 2018), however this reimagining of place in combination with careful curation, such as in the eight festivals under examination here, has been shown by other authors to achieve stronger community inclusion (Devine et al., 2019). Duffy and Mair (2018, p36) argue that festivals can allow for communal expression and offer a place for 'transgressive and subversive messages'. It is our contention that the eight festivals here have been carefully conceived and curated by the organizers to deploy space in such a way that might facilitate placemaking and foster well-being. 
The way that community arts and cultural festivals are consciously located within towns, and then often in smaller neighbourhoods therein, might foster a process for more than just multiple fleeting connections, but also for stories and memories to be shared or, made individually and collectively. Festivals can embody a 'sphere of coexistence of a multiplicity of trajectories' (Massey, 2005, p, 63), generating a Durkheimian collective effervescence whereby participants come together for communal activities that transform and connect at an affective level, potentially building the bonds and transactions essential for the formation of social capital. Specifically, we argue that the organization of an arts festival within the chosen space can facilitate a transformative process, through the stirring of emotion, memories, and perhaps cynefin, of which there is anecdotal evidence in our data. Research has noted that organizers must purposefully embed and enact this process into in the vision and mission of the festival (Jarman, 2018) for it to create any such transformation, as the festival organizers under scrutiny here report that they actively endeavour to do. McClinchey (2015) argues that sense of place is not to do with the perceived authenticity of place but is instead socially constructed by those with a specific interest in the creation of place, belonging and attachment, an approach upon which the eight south-east festivals here are predicated.

Given the austerity measures of the last decade in Britain and the documented impact of widening inequalities on health and well-being across the life course (Marmot, 2018; Marmot, 2010; Wilkinson and Pickett, 2009), it could be argued that arts and cultural festivals have an enhanced, and important, role within in community settings by seeking to create inclusive spaces for the kind of casual social contact during communal arts engagement that can help build trust (APPGAHW, 2017). They have the potential to help the development of mutual and reciprocal connections within communities for the benefit of all. Brownett argued that there is some evidence that local festivals enable community members to unlock healthpromoting assets and develop a 'living legacy' (2018, p, 76). Taking this idea forward, it is argued here that the living legacy might have a double function in festivals orientated around placemaking, in that it might arise individually, bringing attention to a hitherto unknown personal skill or strength, but may be also considered a community resource. In other words, it further emphasizes, and potentially activates, available community assets such as opportunities, people and places, or it might positively influence how the community perceives itself or the future. 
Arts and cultural festivals should therefore not be considered utopian, elitist or exclusive, but seen instead as a key to unlocking community assets, especially when they are conceived and designed as events to attempt to bring local communities together in open and accessible spaces and places within the locality. This is because festivals produce, and liberate, creative spaces that animate these assets, allowing the community to perceive of itself and the available spaces differently. Daily norms are thereby disturbed, and perhaps neutralized, by these heterotopia, within which multiple trajectories allow new personal and communal configurations to be perceived and new interactions to be created. As a result, arts and cultural festivals can create common ground between individuals and groups that might not otherwise meet, and thereby generate enhanced health and well-being benefits within the community as a whole.

Thus far this paper has combined a number of sociological concepts. It has further postulated that they may overlap when applied to the role that arts festivals play in placemaking and community processes important to good health, as understood by local authorities and the NHS. Synthesizing the two theoreticians, Foucault and Massey, with our own findings from the way the festivals have been conceived and organized, we offer these three relationship maps to demonstrate the ways in which we think such community events, designed and curated as the eight festivals here have been, can support well-being.

Through the use of the three conceptual maps we hypothesize that there is a complex relationship between the spaces temporarily occupied by festivals, the communities that live in and around these spaces, and temporary communities, that is, the visitors to the festival, many of whom might come from outside the community. However, it is through these interactions that the potential exists for these community-based festivals to generate a sense of common ground as heterotopia and thus foster well-being benefits.

Map 1. The psychosocial processes of arts festival linking the individual to the community adapted from Brownett (2018, p, 79). In this map, the broken line is an invisible permeable membrane denoting a permanent or temporary community created by the festival. It is important to note here that processes of how the festival creates participation and develops connections that benefit individuals has not been described by this article. The map is presented to provide a framework that the two subsequent maps can be built upon. 
Map 2. The interrelationship of festival spatial themes are mapped against Foucault, Massey, and Durkheim. In this map the broken line remains the permeable membrane between a range of communities, but now denotes the festival heterotopia. This membrane represents the contiguous space that exists alongside, or within, existing space. Almost as if passing through a veil, the space is transformed, perhaps by the festival's ability to showcase stories from the local heritage and those of others from outside (multiple trajectories). Consequently, the individual might potentially be drawn outside themselves, able to see things from a different perspective, by virtue of the cultural experience and a cosmopolitan interaction with others (Appiah, 2007) within the heterotopia. Communal collaboration and engagement with the festival theoretically provides space for social contact and trust building. In map 2 it is shown as collective effervescence but is envisaged to overlay social capital shown in map 1.

In Map 3. The previous two maps are overlaid to show their relationships to one another. Thus, sociological theory, festival processes and the interrelated themes of festival space findings can be seen to demonstrate the festival diffusion effect.

We argue that, as the result of these processes of thinking about the use of space and place in festival design, a festival diffusion effect can be created, whereby prosocial space is transformed and created for the acceptance and welcoming of difference. This acceptance is described by Appiah (2007) as 'habits of co-existence: conversation in its older meaning, of living together, association' (2007: xvii). Our festival diffusion effect shows the theoretical possibilities and opportunities for such community events to cut across divisive boundaries to facilitate a sense of connection and belonging by means of their focus on placemaking. In our theoretical conception, this diffusion effect is dynamic and allows for ideas an experiences to be embraced both within a community and taken outside to the communities beyond. 


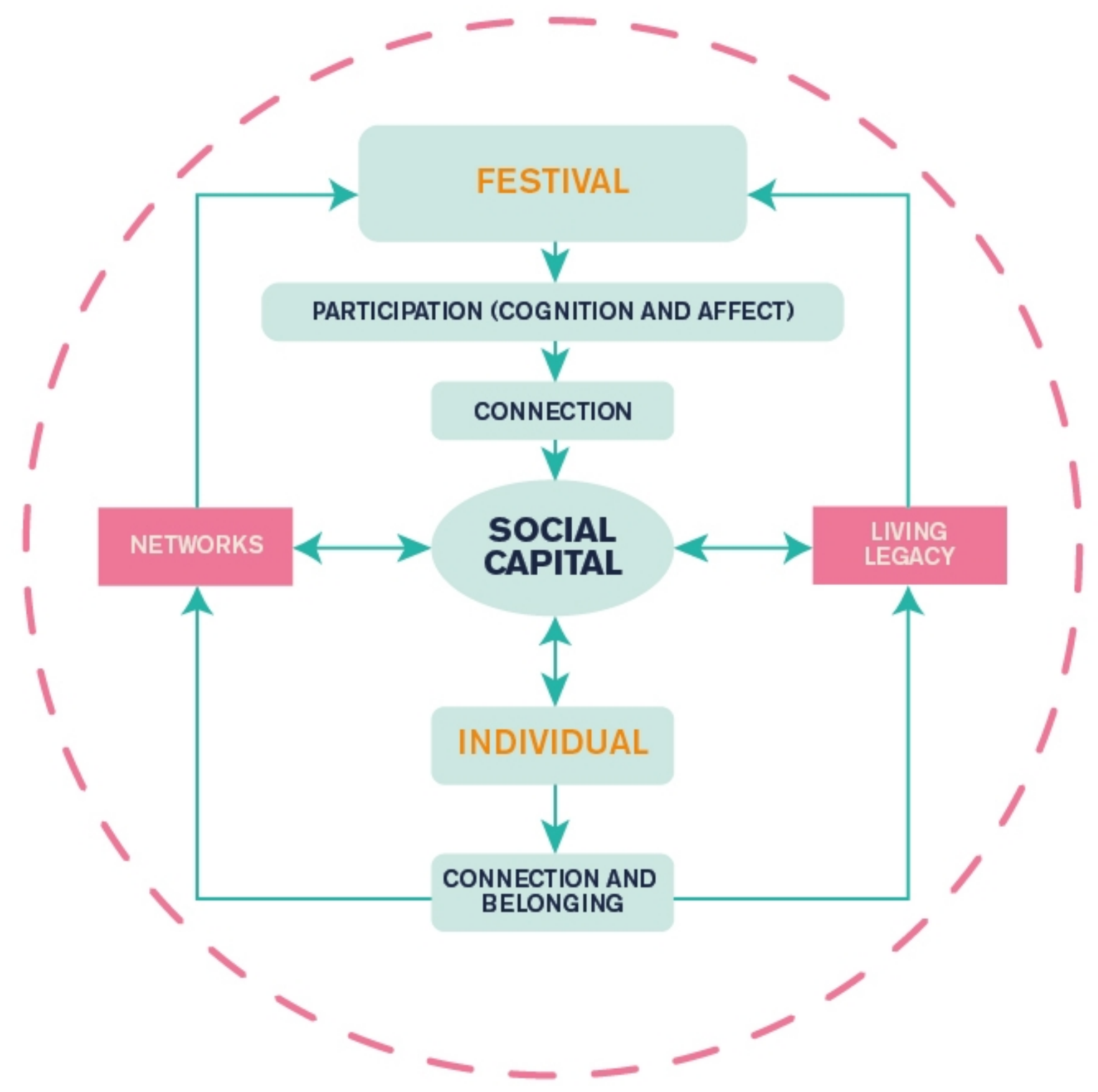

MAP 1. THE PSYCHOSOCIAL PROCESSES OF ARTS FESTIVAL LINKING THE INDIVIDUAL TO THE COMMUNITY 


\section{Model: The Festival Space}

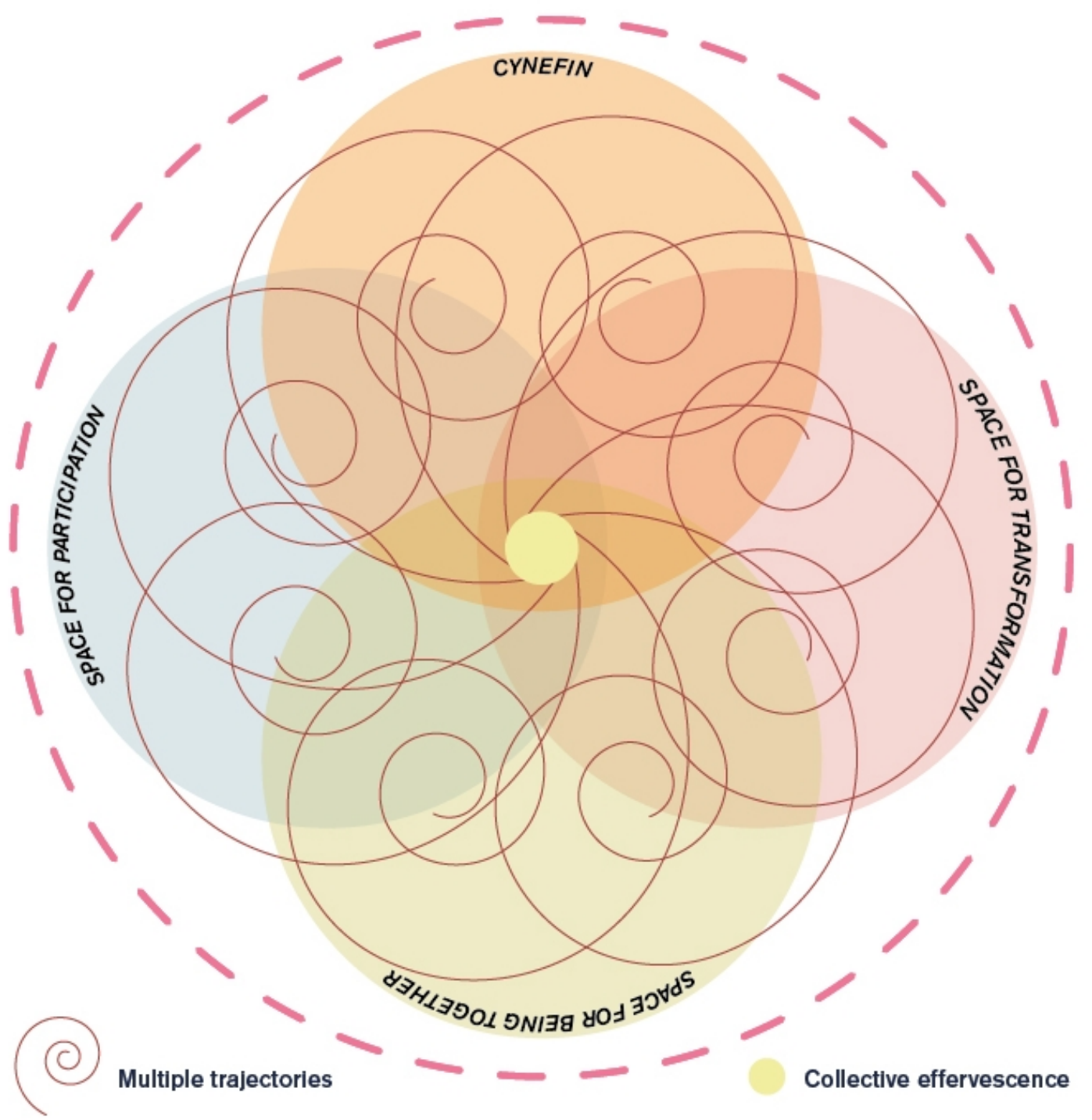

MAP 2. THE INTERRELATIONSHIP OF FESTIVAL SPATIAL THEMES 


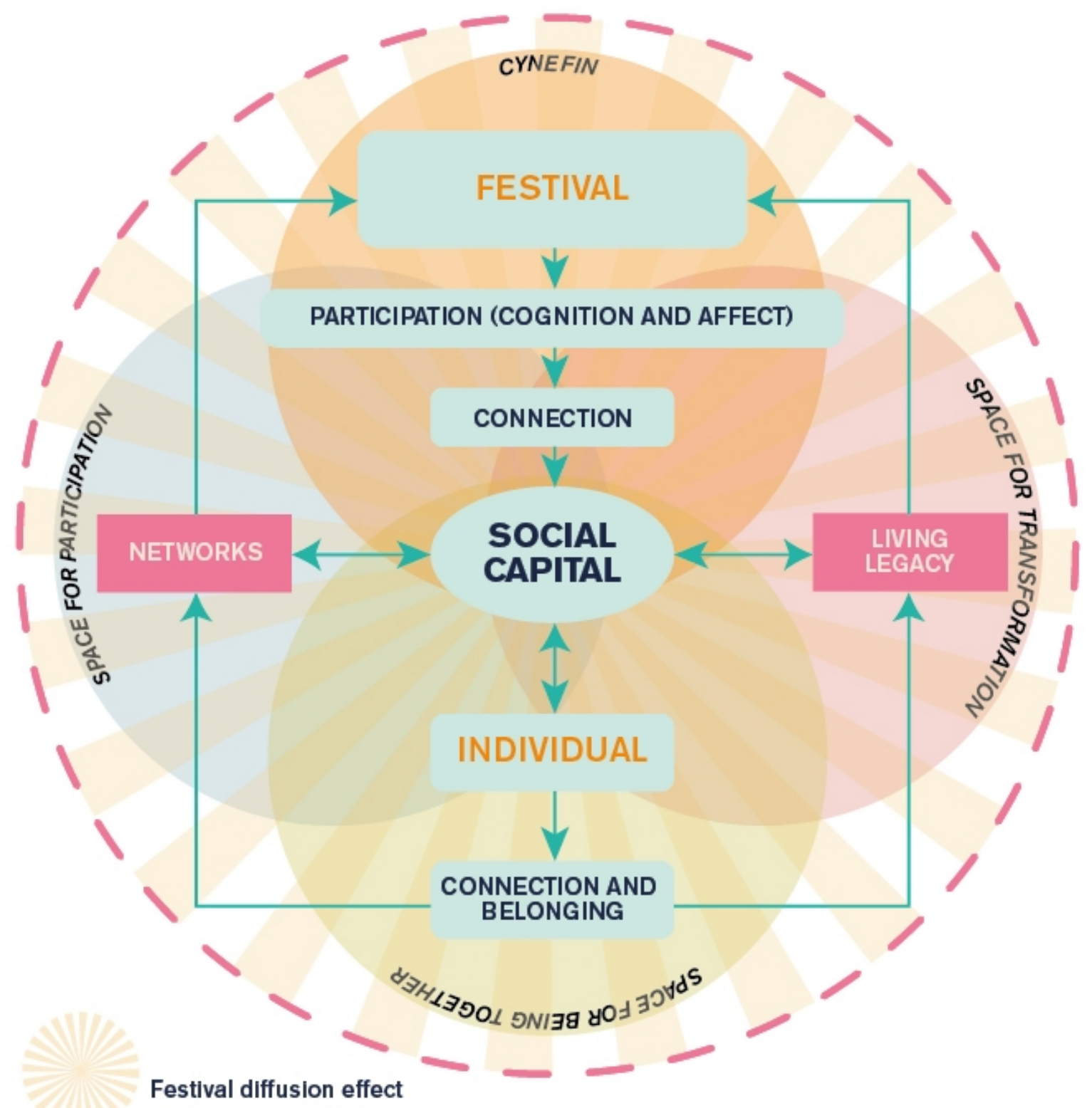

MAP 3. THE OVERLAP BETWEEN SOCIOLOGY THEORY, FESTIVAL PROCESSES AND THE INTERRELATED THEMES OF FESTIVAL SPACE FINDINGS.

\section{Limitations}

The sampling method used for this study meant that the research was confined to a small geographical region. Within this region there are a number of arts regeneration areas which might influence how festivals operate within the place and how audiences engage with the 
festival. This means that it is difficult to argue for the transferability of findings. The data collected was indirect, in that the organizers' perspective was sought rather than their audience, which again could influence our interpretation of the festival space. However, our study is a new enquiry in this field, drawing on the spatial theories of Foucault and Massey in order to posit why the community festival space might succeed in supporting well-being in the ways the APPGAHW report intimates arts and cultural engagement can (2017). Future research to collect data from festival participants will now be required to test fully both our findings and the models we propose.

\section{Conclusion}

Community arts festivals have real potential to contribute to the placemaking agenda. Though this article describes a relatively small study, it argues that through careful use of space, festivals can and do contribute to sense of place and belonging. Furthermore, these spaces potentially allow for wider, and perhaps more equitable, participation, for being together and the facilitation of collective transformation within multiple communities. These findings should be considered important characteristics in how community festivals should, be conceived, designed and curated in order to contribute to placemaking and the unlocking of community assets for wider social well-being.

The article has also proposed theoretical arguments and models to conceptualize the complex interrelationships of spatial theories applied to the ways in which arts and cultural festival organizers have conceived and designed their events, to use accessible public spaces to support placemaking and the generation of well-being. These arguments and the three models help to explain the creation of, what we propose to call, a festival diffusion effect, which is the positive creation or transformation of prosocial spaces that could support community acceptance and well-being, the ability to live together and cohesively and accepting difference. Working in this way, using shared community space, festivals could support participants to find common ground in a variety of ways through cultural engagement and participation, all of which would support the generation and maintenance of well-being. These findings will only perhaps be relevant to festivals that are created by the community for the community rather than field festivals or ticketed events.

\section{Funding and declaration of interest}


This research did not receive any specific grant from funding agencies in the public, commercial, or not-for-profit sectors.

\section{Data}

Need to put information in here about the data set and accessibility - if it is accepted.

\section{Acknowledgements}

To [name redacted] for internal peer review, [name redacted] for the taking untidy conceptual models and making them beautiful, and to our external reviewers for their helpful feedback, which supported the strengthening of this article.

\section{References:}

Alevizou, G., Alexiou, K., Harte, D., Sobers, S. and Zamenopoulos, T. (2016) 'Civic cultures and modalities of placemaking', In: Hargreaves, I. and Hartley, J. (eds) The creative citizen unbound: How social media and DIY culture contribute to democracy, communities and the creative economy. Bristol: Policy Press

The All-Party Parliamentary Group on Arts, Health and Wellbeing (2017), 'Creative health: The arts for health and wellbeing', The All-Party Parliamentary Group on Arts, Health and Wellbeing, unpaginated, https://www.artshealthandwellbeing.org.uk/appg-inquiry/ . (accessed 25 March 2019)

Andrews, K. (2014) Culture and poverty, Wales: Welsh Government, https://gweddill.gov.wales/docs/drah/publications/140313-culture-and-poverty-en.pdf . (accessed 25 March 2019)

Appiah, K. A. (2007), Cosmopolitanism: Ethics in a World of Strangers, London: Penguin Arcodia, C. and Whitford, M. (2006) 'Festival attendance and the development of social capital', Journal of Convention \& Event Tourism, 8(2), pp.1-18 Doi

10.1300/J452v08n02_01

Atkinson, S., Bagnall, A-M., Corcoran, R., South, J., Curtis, S., di Martino, S. and Gerlinde, P. (2017), What is community wellbeing: conceptual review, What Works Wellbeing, https://whatworkswellbeing.org/product/community-wellbeing-concepts-and-questions/ 
(accessed 18 April 2019)

Bagnall, A-M, South, J., di Martino, S., Southby, K., Pilkington, G., Mitchell, B., Pennington, A. And Corcoran, R. (2018) Places, spaces, people and wellbeing: A systematic review of interventions to boost social relations through improvements in community infrastructure (places and spaces), What Works Wellbeing, https://whatworkswellbeing.org/product/places-spaces-people-and-wellbeing/ (accessed 18 April 2019)

Bagnall, A-M., South, J., Mitchell, B., Pilkington, G., Netwon, R. and Di Martino, S. (2017), Systematic scoping review of community indicators of wellbeing in the UK, Version 1.1, August, What Works Wellbeing, unpaginated, https://whatworkswellbeing.org/product/community-wellbeing-indicators-scoping-review/. (accessed 25 March 2019).

Biaett, V. (2019) Festivity and attendee experience: A confessionary tale of discovery, In, Mair, J. (ed) The Routledge Handbook of Festivals, Abingdon: Routledge

Black, N. (2016) 'Festival connections: How consistent and innovative connections enable small- scale rural festivals to contribute to socially sustainable communities', International Journal of Event and Festival Management, 7 (3), 172-187, https://doi.org/10.1108/IJEFM-04-2016-0026

Blokland, T. (2009) 'Celebrating local histories and defining neighbourhood communities: Place-making in a gentrified neighbourhood.' Urban Studies 46(8), 1593-1610 https://doi.org/10.1177/0042098009105499 https://doi.org/10.1177/0042098009105499

Braun,V. and Clarke, V. (2006),'Using thematic analysis in psychology', Qualitative Research in Psychology, 3 (2), 77-101.

British Academy (2017a), Where We Live Now: Perspectives on Place and Policy, London: British Academy, https://www.britac.ac.uk/where-we-live-now (accessed 31 March 2018) British Academy (2017b), Where We Live Now: Making the Case for Place-based Policy, London: British Academy, https://www.britac.ac.uk/where-we-live-now (accessed 31 March 2018)

Bronfenbrenner, U. (1994). Ecological models of human development. In T. Husen \& T. N. 
Postlethwaite (Eds.), International encyclopedia of education (2nd ed., Vol. 3, pp. 16431647). Oxford, UK: Pergamon.

Brownett, T. (2018), Social capital and participation: the role of community arts festivals for generating wellbeing. Journal of Applied Arts and Health, 9 (1), 71-84.

Cantle, T. (2012), Interculturalism: The New Era of Cohesion and Diversity, Basingstoke: Palgrave Macmillan

Cattell, V., Dines, N., Gesler, W. and Curtis, S. (2008) Mingling, observing and lingering: everyday public spaces and their implications for well-being and social relations. Health and Place, 14, 544 - 561. Available at: http://www.sciencedirect.com/science/article/pii/S1353829207000913

Charmaz, K. (2000) 'Constructivist and objectivist grounded theory', In, Denzin, N.K and Lincoln Y. (Eds.) Handbook of Qualitative Research (2nd ed.), Thousand Oaks, Ca: Sage

Corcoran, R. and Marshall, G. (2015) Community Wellbeing: Creating pro-social spaces. London: What Works Wellbeing Available at:

https://whatworkswellbeing.org/blog/community-wellbeing-creating-pro-social-places/ (accessed: 21 June 2018)

Dovidio, J.F., Allyn Piliavin, J.., Schroeder, D.A. and Penner, L.A. (2012) The social psychology of prosocial behaviour. New York: Psychology Press

Derrett, R. (2003) 'Making sense of how festivals demonstrate a community's sense of place. Event Management, 8(1), pp.49-58 dot:1525-9951/03

Derrett, R. (2011), 'Festivals, events and the destination', in Yoeman, I., Robertson, M., Ali-Knight, J., Drummand, S. and McMahon-Beattie, U. (eds) Festival and events management, an international arts and culture perspective. Abbingdon: Routledge Chpt 3

Devine, A. Quinn, B., Devine, F. (2019) leveraging a festival to build bridges in a divided city, In, Mair, J. (ed) The Routledge Handbook of Festivals, Abingdon: Routledge

Duffy, M. and Mair, J. (2018) Festival Encounters. Abingdon: Routledge 
Dyer, L. (2016), 'Pride of the Community', Arts Council England (blog), https://www.artscouncil.org.uk/read-all-blog-posts/pride-community (accessed 21 June 2018)

Ehrenreich, B. (2007), Dancing in the Streets: A History of Collective Joy, London: Granta

Foucault, M. (2008). 'Of other spaces (1967)', in M. Dehaene and L. De Cauter (eds.). Heterotopia and the city: Public space in a postcivil society. London: Routledge, pp.13-29

Friedmann, J. (2010) 'Place and placemaking in cities: a global perspective', Planning Theory and Practice, 11(2), pp.149-165, DOI: 10.1080/14649351003759573

Halton NHS Commissioning Group, (2017) A cultural manifesto for wellbeing, Available at: http://www.haltonccg.nhs.uk/public-

information/Documents/A\%20Cultural\%20Manifesto\%20for\%20Wellbeing.pdf (accessed 3 February 2019)

Heller, A. and Adams, T. (2009) 'Creating healthy cities through socially sustainable placemaking', Australian Planner, 46 (2),18-21, DOI:

10.1080/07293682.2009.9995305

Holden, J. (2019), 'Escaping the Catch-22', Arts Professional. Available at: https://www.artsprofessional.co.uk/magazine/article/escaping-catch22?utm source=Weekly-Good-Reads\&utm medium=email\&utm content=nid210635\&utm campaign=21st-February-2019 (accessed 21 February 2019)

Jarman, D. (2018) 'Festival community networks and transformative placemaking', Journal of Place Management and Development, 11 (3), pp. 335-349 DOI: https://doi.org/10.1108/JPMD-06-2017-0062

Jepson, A. and Stadler, R. (2017) 'Conceptualizng the impact of festival and event attendance upon family quality of life (QOL)', Event Management, 21(1), pp. 47-60 DOI: https://doi.org/10.3727/152599517X14809630271078

Johnson, P. (2006), 'Unravelling Foucault's Different Spaces', History of the Human 
Sciences, 19 (4), 75-90.

Jones, R. and Yates, G. (2013) Briefing Paper 11 - Concepts Series: The built environment and health: an evidence review, Glasgow: Glasgow Centre For Population Health, Available at: https://www.gcph.co.uk/assets/0000/4174/BP 11 -

Built environment and health - updated.pdf (accessed 3 February 2019)

Koohsari, M.J., Mavoa, S., Villanueva, K., Sugiyama, T., Badland, H., Kaczynski, A.T, Owen, N. and Giles-Corti, B. (2015) 'Public open space, physical activity, urban design and public health: Concepts, methods and research agenda', Health and Place, 33, pp. 75 - 82, https://doi.org/10.1016/j.healthplace.2015.02.009.

Laing, J. and Mair, J. (2015), 'Music festivals and social inclusion: The festival organizers' perspective', Leisure Sciences, 37 (3), pp. 252-68, https://doi.org/10.1080/01490400.2014.991009

Local Government Association (2017), People, Culture, Place: The Role of Culture in Placemaking, London: LGA, https://www.local.gov.uk/sites/default/files/documents/12.3\%20\%20culture\%20and\%20place_v4_1_1.pdf (accessed 1 May 2018)

Locality (2018), People Power: Findings from the Commission on the Future of Localism, London: Locality,

https://locality.org.uk/wp- content/uploads/2018/03/LOCALITY-LOCALISM-REPORT-1.pdf (accessed 31 March 2018)

Marmot, M. (2010) Marmot review: fair society: healthy lives, Institute of Health London: Equity. Available at: http://www.instituteofhealthequity.org/resources-reports/fair-societyhealthy-lives-the-marmot-review/fair-society-healthy-lives-full-report-pdf.pdf (accessed 3 February 2019)

Marmot, M. (2018) The health gap: the challenge of an unequal world. London: Bloomsbury Publishing 
Massey, D. (2005), For Space, London: Sage

McClinchey, K.A. (2015) Something greater than the sum of its parts, In Jepson, A. And Clarke A. (eds) Exploring community festivals and events. Abingdon: Routledge.

Mulligan. M. Humphrey, K., James, P., Scanlon, C., Smith, P. and Welch, N. (2006), Creating Community: Celebrations, Arts and Wellbeing Within and Across Local Communities, Melbourne: The Globalism Institute, https://www.creativecity.ca/database/files/library/creating community.pdf (accessed 25 March 2019)

NHS England (2018) Putting health into place; introducing NHS England's Healthy New Towns Programme. NHS England Publications Gateway 08473 Available at: https://www.england.nhs.uk/wp-content/uploads/2018/09/putting-health-into-place.pdf (accessed 4 November 2018)

Platt, L. and Knight, J. (2018) 'Guest editorial', Journal of Place Management, 11(3), pp.262-265 DOI https://doi.org/10.1108/JPMD-08-2018-131

Quinn, B. (2019) Festivals and social sustainability, In, Mair, J. (ed) The Routledge Handbook of Festivals, Abingdon: Routledge

Russell, C. (2011) 'Pulling back from the edge: an asset-based approach to ageing well', Working with Older People, 15(3), pp. 96-106 DOI 10.1108/13663661011176642

Ryff, C.D. and Singer, B.H. (2006) 'Know thyself and become what you are: A eudaimonic approach to psychological wellbeing', Journal of Happiness Studies, 9, pp: 13-39 DOI: 10.1007/s10902-006-9019-0

Wilkinson, R. and Pickett, K. (2011) The spirit level: Why equality makes societies stronger, New York: Bloomsbury Press 


\title{
Finding Common Ground: Community Arts Festivals as Spaces for Placemaking
}

\begin{abstract}
The present research posits the significant role that arts and cultural festivals play in contributing to placemaking and generating well-being within communities. Placemaking is recognized to be important when considering how to improve population health and well-being, and festivals can be seen to amplify those benefits. Drawing on qualitative data gathered from interviews with festival organizers in SouthEast England and deploying theories of space from Foucault and Massey, the present article argues that community arts and cultural festivals support the positive creation or transformation of pro-social spaces that could support community acceptance and well-being, the ability to live together and cohesively and accepting difference.
\end{abstract}

\section{Highlights}

- The study identified four key themes demonstrating that through their use of space, arts and cultural festivals contribute to community sense of well-being and place.

- Festivals instil a connection and sense of belonging to place for local communities through history, heritage and the traditions presented.

- The study suggests access to, and participation in the arts is enhanced by using everyday and familiar places.

- How festivals reimagine and use space is important to developing community and potentially to a placemaking agenda for enhancing public health.

- This paper conceptualizes the complex interrelationships of spatial theories specifically applied to arts and culture festivals for placemaking.

\section{Keywords}

Arts festivals; placemaking; community well-being; heterotopia; community assets 


\section{Introduction}

Placemaking has become a popular concept in discussions that link community studies with arts and culture, as well as health and well-being. Whilst subject to varying definitions, particularly relating to town planning, placemaking broadly relates to the assets within a community, the organisation and accessibility of community spaces, and how these contribute to health and well-being (Corcoran and Marshall, 2015).

Placemaking is now recognized to be extremely important when considering how to improve population health and well-being. Place, and in particular its characteristics and design, shape how we live our lives and can influence behaviours of people that live in them (Heller and Adams, 2009). However, placemaking is more than bricks and mortar. It is about all of the physical and environmental characteristics of the place such as the opportunities to walk and cycle with access to green and public spaces (Koohsari et al., 2017), the access to affordable, healthy food, and the ready access to employment, goods and services (Jones and Yates, 2013). Furthermore, it is about the creation of pro-social spaces that provide opportunities to co-operate, communicate, share experiences, culture, memories and heritage (Corcoran and Marshall, 2015) and thus reduce social isolation and the number of groups leading parallel lives. Placemaking is also about the creation of active participation in civic decision-making and the opportunities for that to be shared equitably within a community (Alevizou et al., 2016; Locality, 2018). Placemaking is a collective process (Blokland, 2009) and therefore, should be actively planned and organized with community, so that people do not have a sense that they are having ideas and initiatives imposed upon them from above or outside (Andrews, 2014).

A number of relatively recent reports from a diverse array of bodies and organisations have focused on the importance that place can play in our everyday lives (e.g. British Academy, 2017a; Dyer, 2016; Local Government Association, 2017; Locality, 2018). Baroness Andrews' Culture and Poverty report for the Welsh Assembly Government in 2014 served to initiate public interest originally 
in Wales, but then further afield. She highlighted the importance of what the Welsh call cynefin, a difficult word to translate into English, but one which evokes the sense of local pride and belonging emanating from history and heritage within communities, as well as the memories and stories of those who live there. The British Academy's Where We Live Now report (2017b) highlights the ways in which 'places matter':

[Places] shape the way we live our lives, feel about ourselves and the relationships we have with others. Moreover, places - not least because of their history, character and physical form - contribute significantly to personal and societal well-being. [...] Most of us have immense affection for the places where we live: they might be places where we grew up, live or work now; where we have family and other relationships; and places are full of memories, stories and our lived experiences. (2017b, p, 1-2)

With its focus on spatially inspired well-being, the British Academy report chimes closely with the recent Creative Health report by the All-Party Parliamentary Group on Arts, Health and Wellbeing (APPGAHW), which underlines 'the power of space to be uplifting' by 'profoundly engag[ing] the senses of sight, touch and sound' (2017, p,65). All of these different reports lay a common emphasis on the importance of a sense of place to well-being. However, to date, there is little focus on the way that particular spaces or sites might inspire a deepening of such wellbeing, a gap this article seeks to address. Taking as its focus arts and cultural festivals in the community, the study reported here examines the extent to which they can stimulate or contribute to well-being in this placemaking context ${ }^{1}$.

\footnotetext{
${ }^{1}$ In For Space, Massey elucidates in her introduction the supposed distinction between space and place, before indicating that her study was inspired by a decision to resist the distinction, especially as 'place' was traditionally seen as meaningful and 'space' as somehow abstract and meaningless (2005: 6). So, for the purposes of this article and its specific focus, we use the two terms as synonyms, siding with Massey, whilst acknowledging their potentially different nuances and uses in other contexts. There is simply not sufficient scope in this article to engage with well-worn discussions about any semantic differences between the two terms, where our principal focus is necessarily on. community festivals, placemaking and well-being.
} 
Drawing specifically on spatial theories of Michel Foucault and Doreen Massey, and underpinned by qualitative data drawn from a small study of eight community festival organizers in SE England, we posit which characteristics of community festivals might be able to facilitate the development, and deepening, of cynefin. Furthermore, we suggest that community festivals might thereby contribute to a 'Iiving legacy'(Brownett, 2018, p, 76) and the creation of an enduring community of cultural citizenship. The article explores the extent to which festivals of this kind might be regarded as 'therapeutic landscapes' (Williams, cited in Cattell et al., 2008, p, 546), which are deemed to comprise 'natural and built environments; social environments; and symbolic environments' (Cattell et al 2008, p, 546). We argue that community-based arts festivals are concrete and metaphorical focal points with the capacity to bring different individuals and groups together, to promote health and well-being, and foster social capital and community cohesion.

Theoretically, the important spatial role for festivals can be mapped through the work of Foucault (2008) and Massey (2005). In their different ways, their theories envisage space as having transformational potential. It is our contention that Foucault's concept of the 'heterotopia' can meaningfully be applied to the way local arts festivals can transform community space (Foucault, 2008). He perceived heterotopia as sites contiguous with everyday spaces; connected to, and yet apart from, those spaces. These spaces facilitate transformation through the activities that they engender. By changing our perception of familiar spaces, heterotopic sites thus have the ability to draw us out of ourselves and potentially generate a capacity for self-evaluation precisely by splintering the familiar. They help us to see things differently, potentially challenge our prejudices, and thus can change the way we view the world around us. ${ }^{2}$ Similarly, Massey's work on space explains how our perceptions of the world might also be transformed. She lays her emphasis on the way that space has the potential to bring us into contact with others, whom we might not otherwise encounter, and thereby to experience 'a collection of interwoven stories of which that place is made' $(2005, p, 119)$. By

\footnotetext{
2 Peter Johnson's analysis of Foucault's inchoate concept of heterotopia has been very helpful in our own deployment of it in this present context. See Johnson (2006).
} 
combining these two theoretical perceptions of the way space can be experienced and reimagined, we argue that festivals have the potential to bring people together, and that these gatherings can positively influence our perceptions of the world around us. This contention chimes with evidence in Creative Health that reinforces how 'casual social contact at local level is central to building trust. Arts engagement, which often involves casual social contact at a local level, is regularly cited as a forum for building trust' (APPGAHW, 2017, p, 79).

There remain challenges to building trust within communities, especially in the wake of the EU referendum in 2016, which starkly highlighted social divisions within the UK (Holden 2019). In his work on interculturalism, Ted Cantle has highlighted, in particular, how certain groups lead parallel lives within communities that lack spaces where bridges can be built between disparate groups (Cantle, 2012). Such bridges are needed to generate opportunities for meaningful contact in order to reduce suspicion and prejudice. By encountering what Massey describes as the 'multiplicity of trajectories' (2005: 63) that coexist in spaces, we are confronted constructively with the lives and stories of others. It is our contention, therefore, that community arts and cultural festivals have transformative potential, by adapting space, or our perception thereof, while at the same time creating an opportunity for casual social contact and trust-building through cultural engagement. As such, it recalls Emile Durkheim's notion of 'collective effervescence' (Ehrenreich, 2007, p.2). However, by bringing people together in this way community arts festivals not only contribute to developing stronger social bonds, but also have a unique potential to contribute to well-being, since 'social relations in a multiplicity of aspects will nurture good health and social care ecologies' (APPGAHW, 2017, p, 80).

The existing evidence base about community arts festivals is limited, tending to focus on the economic and tourism benefits of festivals, rather than the production of well-being and social connections, particularly in poorer areas. Following unexpected findings from a research study intended to investigate social capital for generating well-being (Brownett, 2018), the paper responds to this lacuna. Specifically, we examine how community arts festivals deploy, and liberate access 
to, space and indicate the well-being benefits that can accrue as a result. Community arts and cultural festivals operating in everyday accessible places can, we argue, provide a basis for meaningful communal connection and contribute to collective well-being in communities.

\section{Methods}

Prior to this study, university ethical approval was obtained. One-to-one interviews with eight arts and culture festival organizers based in the southeast of England were undertaken. Laing and Mair (2015, p, 257 citing Szaryzc, 2009) indicate that a small number of participants for this type of study are typical. Each arts festival offering, takes place in towns and cities and is available free of charge or at low cost (see table 1). The participants for this study were identified via social networks and through snowball sampling. No financial incentive was offered to them.

\begin{tabular}{|c|l|l|}
\hline Festival & Cultural Offering & Location \\
\hline P1 & Opera, Dance, Theatre, Community Arts & Coastal Town \\
\hline P2 & $\begin{array}{l}\text { Opera, Dance, Theatre, Community Arts, Parade, } \\
\text { Visual Arts }\end{array}$ & City \\
\hline P3 & $\begin{array}{l}\text { Parade, Community Arts, Street Theatre, } \\
\text { Community Production }\end{array}$ & Coastal Town \\
\hline P4 & Music & City \\
\hline P5 & Parade, Community Arts, Street Theatre & Coastal Town \\
\hline P6 & Music, Visual Arts & Coastal Town \\
\hline P7 & $\begin{array}{l}\text { Three interlinked festivals, Music, Dance, Theatre, } \\
\text { Community Arts, Visual Arts, Community } \\
\text { Production }\end{array}$ & Coastal Town \\
\hline P8 & $\begin{array}{l}\text { Community Arts, Visual Arts } \\
\text { Poastal Town }\end{array}$ \\
\hline
\end{tabular}




\section{Table 1. Festival Offering}

The interviewer conducted semi-structured interviews lasting between 30-60 minutes. Open directive questions were asked around the themes of the type of festival offering, the intended audience, the aims of the festival, the unintended consequences of the festival, festival evaluation and whether the generation of well-being was an aspiration. The purpose of this interview approach was to enable participants to provide their own narrative and thick description (Geertz, 1983). The interviews took place in a venue of the interviewee's choice to facilitate their ease and candid contribution. A portable recording device was used to capture the interview, which was then transcribed verbatim. Interviewees were encouraged to indicate where commercially sensitive or confidential information had been revealed so that this could be redacted prior to analysis. An earlier pilot study had revealed this to be of upmost importance to festival organizers, as funding for arts festivals is highly competitive. All data was treated as confidential.

In order to identify major themes the interview transcripts were re-read and audio recordings played to ensure familiarity with the data. A coding handbook and inductive open coding identified patterns of meaning and further descriptive codes were assigned. In sum, 17 codes were identified, later collated into four themes. Two coders agreed on the themes, using thematic analysis with a specific methodology grounded in a theory-driven approach (Braun and Clarke 2006).

\section{Findings}

Below we discuss the four key findings of our thematic analysis which we named, Cynefin, Spaces for Participation, Spaces for Being Together and Spaces for Transformation. The discussion that follows illustrates how these themes are important in terms of the contribution of community arts and culture festivals to a sense of place and well-being. It is important to recognize that although we write about them as discrete themes, they are overlapping concepts. 


\section{Cynefin}

Throughout the interviews there was a strong articulation of cynefin, even if it was not described using this term. Respondents referred to a strong sense of place and belonging, interwoven with memories, stories, history and heritage within the community. The importance of history, heritage or the traditions of places were central to festival construction and imagination:

"[The festival was] connected with the dockyard [...] it was absolutely heaving with people [dressed as] sailors and ladies[...]dressed as whores going up to the men and saying 'round the back for a sixpence'. Everyone had such good fun [...] the old boys loved it, 'cause they were sailors." [P5]

The importance of wanting to show off the geographical place to outsiders and celebrate its particular qualities was also a key motive.

"[...] that was the other thing, the result of the summer festival, was to do something that showed the best of the place and started to reveal what it has to offer [...]people outside have a low perception of the place. Or they have a negative perception. And that's a really powerful reason for us to do it. You have to be rooted in the place but the primary actual reason was to go, look at this amazing place."(P1)

Festival organizers interviewed reported that the location of their festival was often decided by the availability of low-cost or free local places. However, they reported that they specifically chose to celebrate the location, its heritage, and the stories and memories that permeate these places. Therefore the use of community spaces naturally complements and amplifies this ethos.

The personal connection of belonging to a place and its community is argued to be one of the domains essential to good health and well-being (Atkinson et al., 2017). Furthermore it is one of the key principles of the Healthy New Towns initiative 
(NHS England, 2018). However, Atkinson highlights that the common values, understandings of place and cultural heritage are essential for realising community well-being and yet may prove exceedingly complex to evaluate empirically (Atkinson et al., 2017).

\section{Participation}

As already discussed festival organizers use community spaces for their events and report that they often liberate local spaces out of necessity. This is both a financial decision, but often also as a result of a lack of, or restricted access to, cultural assets and purpose built venues. The consequence of using local spaces and sites actually has the potential to increase participation and engagement with the arts.

Distilled from the 'multiplicity of trajectories' described by Massey (2005: 5), this theme describes both the spaces that allow people to bump into one another:

"[...] you start to get this blending between people who initially thought that wasn't for them and they didn't understand, [but] are now completely part of it. And that activity in that pub connects those people to lives, to the wider challenges that are happening all the time."(P7)

and extends to an intended development of a safe space to animate individual, and collective, participation.

"But the beautiful kind of hidden, or you know, the added value that was unexpected [...] that we'd engaged in such a kind of genuine familyoriented way; they all then felt so comfortable with us as a group that came into [the gallery] and they experienced a totally new cultural experience and engaged with people that they probably would never speak to. Because they were in this kind of safe environment that was actually facilitated by their children. And to me that's what regeneration or, you know, social change is about. It's about engaging young people 
and then the older generations kind of follow and I think that's how it needs to happen now."(P8)

Atkinson has noted in her systematic review that there is evidence that events such as festivals generate neutral spaces for people to socialize, and in particular the use of natural spaces fosters active participation (Atkinson et al., 2017). However, whilst she provides no evidence for participation being a specific output of the chosen space, she acknowledges the sort of places that the festival organizers in our research sought out can be defined as 'community infrastructure', that is, 'public places and 'bumping "places designed for people to meet, including streets, squares, parks, play areas, village halls and community centres'(Atkinson et al., 2017, p21).

\section{Being Together}

In this theme festival organizers sought to create a momentary sense of community by purposely liberating the space for celebration in sites where that might not ordinarily happen.

"[our strength] is that we have connections on all the different art forms. So whether it's music or theatre or visual arts, we do the walks, we do science. But the idea is just to get everyone together. Because it's a community festival." (P2)

"[...] I'm not gonna ticket it. Because a) it wouldn't be inclusive and, b) if it did, [it would be] in a cage on the beach. Because how could you ticket the beach? Because you'd literally have to cage off the sea. There's no way I'm doing a free spirit festival and being in a cage on the beach, you know what I mean? There's no way we can do that."(P6)

The spaces used in this way are often already deemed communal or open, democratic spaces but not generally used for arts and cultural activities: 
"One lady said, oh, I saw this amazing thing [...] there was this guy sitting in a chair, dressed as a polar bear telling stories. It was us. We put a yurt outside Debenhams at one of the festivals [...] and she said my kids loved it, it's the best thing I have ever seen in my entire life." (P1)

This theme evidences that community events can facilitate improved social interactions (Bagnall et al., 2018). Cattell et al. (2008) describe the importance of the everyday places within a community for bringing people together to develop and maintain friendships, even in the most fleeting of encounters. In this way, quotidian settings comprise potential opportunities for escape, but are also essential in connecting people to the place where they live. The everyday spaces that local community arts festivals liberate and reimagine allow such interactions to be fostered and strengthened, especially where people lead parallel lives or strong social bonds do not already exist. The findings of our own study appear to show that festival spaces contribute to the development of relationships with others.

This is not perhaps surprising given that arts festivals provide space for human connection through shared cultural experiences, the transfer of personal memories and a sharing of stories, which ultimately celebrate the community and its heritage (Black, 2016). Story-telling and the sharing of cultural memory is recognized as essential to the ongoing development of community. Stories and shared memories are the glue that connects people and potentially mobilizes neighbourhoods to act with collective interest (Russell, 2011). Furthermore, this story-telling and participation in festival events provides opportunities for communities to define, create and present their sense of collective self, and the place that they are from (Derrett, 2009).

\section{Space for Transformation}

Using the concept of heterotopia, we suggest that the arts and cultural festivals at the heart of this research reimagine everyday spaces, by using activities or events to create a permeability within what might ordinarily be considered a fixed and 
boundaried space with a set function, be it a beach, a shopping centre or a pub. This permeability enables the festival participant to safely step outside of their everyday self by entering the festival-generated heterotopia and engaging with the cultural experience. As an example, one of the festival organizers interviewed described an art installation by local adolescents, in a deprived coastal area, as a walk 'up the hill':

"[for visitors to] experience the town further afield because generally that tends to be the criticism...that people don't go any further than the [gallery]...so the idea was that they would go up the hill, which is how the kids would describe it - going up the hill[...] to experience a bit more of the cultural value of the area."[P8]

Arts festivals provide an opportunity for conversations about how the community are perceived or perceive themselves:

"So we did a consultative piece of work as an art installation, it was called love, hate, hope. And it was a ten-minute film that questioned, just interviewed people, just about love, hate, hope. [...] a fantastic designer [...] converted the shop, did a beautiful window. It was back projected on a 9 feet high TV screen and we also got them to write on a postcard love, hate, hope' and we analysed 928 comments. Two words came out, [...] "apathy" and "dirty" from every respect [...].[We created] a leading art form where people participated, were interested in, or visited creative writing and place.'(P1)

This finding also describes how the festival creates an atmosphere that inspires conversations and facilitates transformation in the participants:

"[...] but it's just the atmosphere draws them into chilling out [...] over a space of time, [...] and they encourage each other too and it's like it takes over, you know, it's magic."(P6) 
However the festival's use of space, combined with the specific cultural offering, stimulates a wider, more communal, transformation of how the community sees itself:

"the [cultural] landscape here is changing [...] I would say that our summer festival is driving that change."(P1)

It can be seen that arts and cultural festivals are a form of community celebration (Mulligan et al., 2006), and the appropriation of space is critical to the identity of the festival:

"and it comes back to the idea of what would happen if you break down the walls of the art centre and invite the community to help you programme the space."[P7]

\section{Discussion}

The four identified themes of our research - Cynefin, spaces for participation, being together, and transformation - show that arts and cultural festivals in particular can both support and demonstrate their essential role within the placemaking agenda. The Halton Cultural Manifesto for Wellbeing (Halton NHS Commissioning Group, 2017) provides a good example, by setting out how the arts in general can support residents to imagine new kinds of connected communities; to develop their own strengths and abilities, so that they can live independent lives and develop health resources.

Through the reimagining and repurposing of space, festivals have huge potential to create new (or renewed) physical and emotional connections, as well as generating a sense of belonging, irrespective of race, gender or class, by changing our perspectives. The heterotopic space thus established can be truly inclusive and intercultural, uniting Foucault and Massey's respective interpretations of space. 
The way that arts and cultural festivals are consciously located within towns, and then often in smaller neighbourhoods therein, enables a process for more than just multiple fleeting connections, but also for stories and memories to be shared or, made individually and collectively. Festivals thus embody a 'sphere of coexistence of a multiplicity of trajectories' (Massey, 2005, p.63), generating a Durkheimian collective effervescence whereby participants come together for communal activities that transform and connect at an affective level, potentially building the bonds and transactions essential for the formation of social capital. Specifically, we argue that the organization of the arts festival within the chosen space facilitates a transformative process, through the stirring of emotion, memories, and perhaps cynefin.

Given the austerity measures of the last decade in Britain and the documented impact of widening inequalities on health and well-being across the life course (Marmot, 2018; Marmot, 2010; Wilkinson and Pickett, 2009), it could be argued that arts and cultural festivals have an enhanced, and important, role to play within in community settings. They have the potential to help the development of mutual and reciprocal connections within communities for the benefit of all. Brownett argued that there is some evidence that local festivals enable community members to unlock health-promoting assets and develop a 'living legacy' $(2018$, p, 76). Taking this idea forward, it is argued here that the living legacy has a double function in that it might arise individually, bringing attention to a hitherto unknown personal skill or strength, but may be also considered a community resource. In other words, it further emphasizes, and potentially activates, available community assets such as opportunities, people and places, or it might positively influence how the community perceives itself or the future.

Arts and cultural festivals should therefore not be considered utopian, elitist or exclusive, but seen instead as a key to unlocking community assets. This is because festivals produce, and liberate, creative spaces that animate these assets, allowing the community to perceive of itself and the available spaces differently. Daily norms are thereby disturbed, and perhaps neutralized, by these heterotopia, within which multiple trajectories allow new personal and communal 
configurations to be perceived and new interactions to be created. As a result, arts and cultural festivals can create common ground between individuals and groups that might not otherwise meet, and thereby generate enhanced health and wellbeing benefits within the community as a whole.

Thus far this paper has combined a number of sociological concepts. It has further postulated that they may overlap when applied to the role that arts festivals play in placemaking and community processes important to good health, as understood by local authorities and the NHS. Synthesising the two theoreticians (Foucault and Massey) with our own findings we offer these three relationship maps to demonstrate:

Through the use of the three conceptual maps it can be seen that there is a complex relationship between the spaces temporarily occupied by festivals, the communities that live in and around these spaces, and temporary communities, that is, the visitors to the festival, many of whom might come from outside the community.

Map 1. The psychosocial processes of arts festival linking the individual to the community - adapted from Brownett (2018, p, 79). In this map, the broken line is an invisible permeable membrane denoting a permanent or temporary community served by the festival.

Map 2. The interrelationship of festival spatial themes mapped against Foucault, Massey, and Durkheim. In this map the broken line remains a permeable membrane between a range of communities, and denotes the festival heterotopia. This membrane represents the contiguous space that exists alongside, or within, existing space, but almost as if passing through a veil, the space is then transformed and consequently the individual is drawn outside themselves and able to see things from a different perspective, by virtue of the cultural experience and a cosmopolitan interaction with others (Appiah, 2007) within the heterotopia. 
In Map 3. The previous maps are overlaid to show their relationships to one another. Thus sociological theory, festival processes and the interrelated themes of festival space findings can be seen to demonstrate the festival diffusion effect.

We argue that, as the result of these processes, a festival diffusion effect is created, whereby pro-social space is transformed and created for the acceptance and welcoming of difference. This acceptance is described by Appiah (2007) as 'habits of co-existence: conversation in its older meaning, of living together, association' (2007: xvii). Our festival diffusion effect shows the theoretical possibilities and opportunities to cut across divisive boundaries to facilitate a sense of connection and belonging. This diffusion effect is dynamic and allows for ideas and experiences to be embraced both within a community and taken outside to the communities beyond.

Map 1. The psychosocial processes of arts festival linking the individual to the community

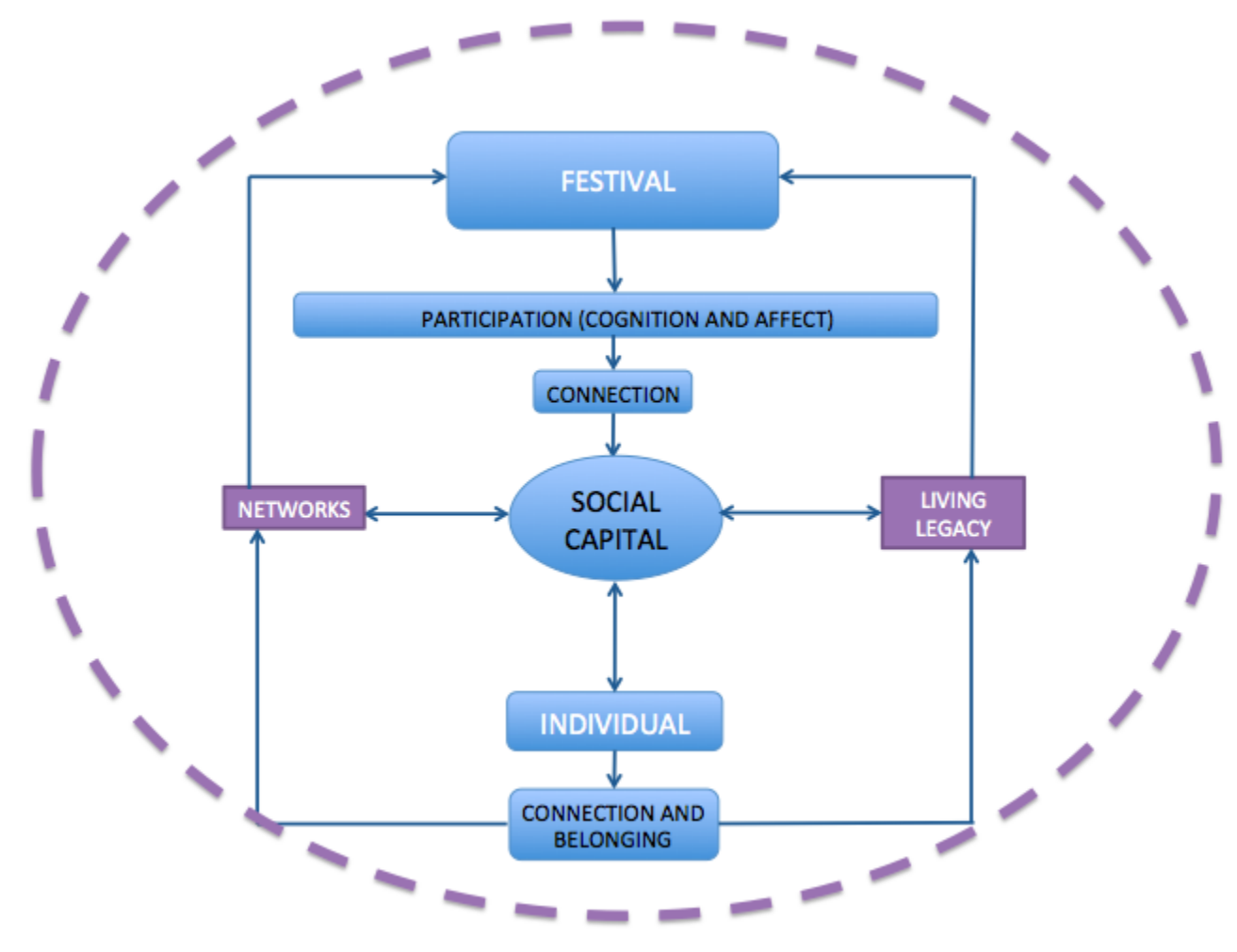


Map 2. The interrelationship of festival spatial themes

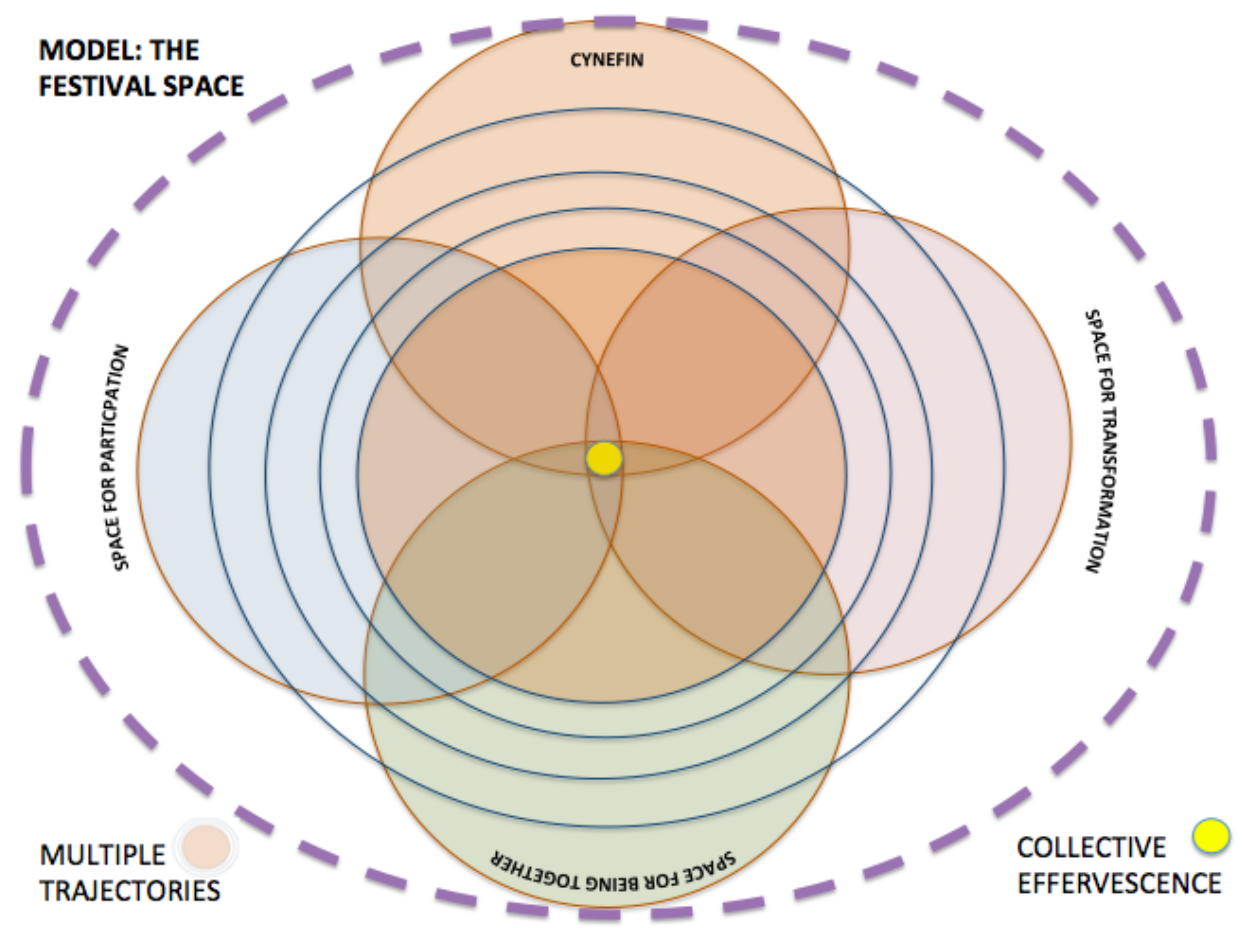

Map 3. The overlap between sociology theory, festival processes and the interrelated themes of festival space findings.

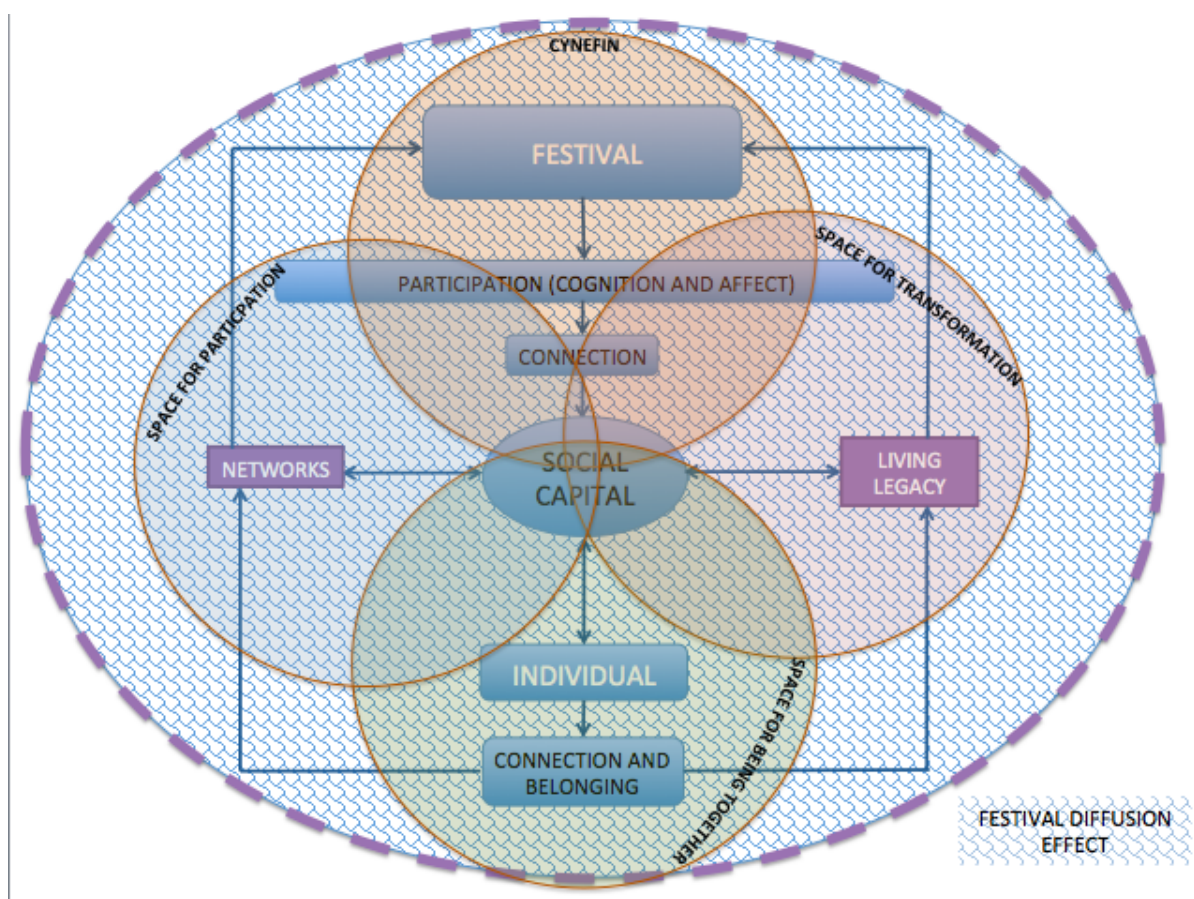




\section{Limitations}

The sampling method used for this study meant that the research was confined to a small geographical region. Within this region there is a number of arts regeneration areas which might influence how festivals operate within the place and how audiences engage with the festival. This means that it is difficult to argue for the transferability of findings. The data collected was indirect, in that the organizers' perspective was sought rather than their audience, again could influence our interpretation of the festival space. However, our study is a new enquiry in this field and as such future research is required. Further data collection from festival participants would test both our findings and the models.

\section{Conclusion}

Community arts festivals have real potential to make a contribution to the placemaking agenda. Though this article describes a relatively small study, it demonstrates that through careful use of space, festivals can and do contribute to sense of place and belonging. Furthermore, these spaces allow for wider and perhaps more equitable participation, for being together and the facilitation of collective transformation within multiple communities. These four findings should be considered important characteristics in how festivals contribute to placemaking and the unlocking of community assets for wider social well-being.

The article has also proposed theoretical arguments and models to conceptualize the complex interrelationships of spatial theories applied to arts and culture festivals, spatial characteristics. These arguments and the three models help to explain the creation of, what we call, a festival diffusion effect, which is the positive creation or transformation of pro-social spaces that could support community acceptance and well-being, the ability to live together and cohesively and accepting difference. Working in this way, using shared community space, festivals support participants to find common ground in a variety of ways through cultural engagement and participation.

\section{Funding and declaration of interest}


This research did not receive any specific grant from funding agencies in the public, commercial, or not-for-profit sectors.

\section{Data}

Need to put information in here about the data set and accessibility - if it is accepted.

\section{Acknowledgements}

To $\mathrm{x}$ for internal peer review.

\section{References:}

Alevizou, G., Alexiou, K., Harte, D., Sobers, S. and Zamenopoulos, T. (2016) 'Civic cultures and modalities of placemaking', In Hargreaves, I. and Hartley, J. (eds) The creative citizen unbound: How social media and DIY culture contribute to democracy, communities and the creative economy. Bristol: Policy Press

The All-Party Parliamentary Group on Arts, Health and Wellbeing (2017), 'Creative health: The arts for health and wellbeing', The All-Party Parliamentary Group on Arts, Health and Wellbeing, unpaginated, https://www.artshealthandwellbeing.org.uk/appg-inquiry/ . (accessed 25 March 2019)

Andrews, K. (2014) Culture and poverty, Wales: Welsh Government, https://gweddill.gov.wales/docs/drah/publications/140313-culture-andpoverty-en.pdf . (accessed 25 March 2019)

Appiah, K. A. (2007), Cosmopolitanism: Ethics in a World of Strangers, London: Penguin

Atkinson, S., Bagnall, A-M., Corcoran, R., South, J., Curtis, S., di Martino, S. and 
Gerlinde, P. (2017), What is community wellbeing: conceptual review, What Works Wellbeing, https://whatworkswellbeing.org/product/community-wellbeingconcepts-and-questions/ (accessed 18 April 2019)

Bagnall, A-M, South, J., di Martino, S., Southby, K., Pilkington, G., Mitchell, B., Pennington, A. And Corcoran, R. (2018) Places, spaces, people and wellbeing: A systematic review of interventions to boost social relations through improvements in community infrastructure (places and spaces),What Works Wellbeing, https://whatworkswellbeing.org/product/places-spaces-people-andwellbeing/ (accessed 18 April 2019)

Bagnall, A-M., South, J., Mitchell, B., Pilkington, G., Netwon, R. and Di Martino, S. (2017), Systematic scoping review of community indicators of wellbeing in the $U K$, Version 1.1, August, What Works Wellbeing, unpaginated, https://whatworkswellbeing.org/product/community-wellbeing-indicatorsscoping-review/. (accessed 25 March 2019).

Black, N. (2016) 'Festival connections: How consistent and innovative connections enable small- scale rural festivals to contribute to socially sustainable communities', International Journal of Event and Festival Management, 7 (3), 172-187, https://doi.org/10.1108/IJEFM-04-2016-0026

Blokland, T. (2009) 'Celebrating local histories and defining neighbourhood communities: Place-making in a gentrified neighbourhood.' Urban Studies 46(8), $1593-1610$

Braun,V. and Clarke, V. (2006),'Using thematic analysis in psycho- logy', Qualitative Research in Psychology, 3 (2), 77-101.

British Academy (2017a), Where We Live Now: Perspectives on Place and Policy, London: British Academy, https://www.britac.ac.uk/where-we-live-now (accessed 31 March 2018)

British Academy (2017b), Where We Live Now: Making the Case for Place-based 
Policy, London: British Academy, https://www.britac.ac.uk/where-we-live-now (accessed 31 March 2018)

Brownett, T. (2018), Social capital and participation: the role of community arts festivals for generating wellbeing. Journal of Applied Arts and Health, 9 (1), 7184.

Cantle, T. (2012), Interculturalism: The New Era of Cohesion and Diversity, Basingstoke: Palgrave Macmillan

Cattell, V., Dines, N., Gesler, W. and Curtis, S. (2008) Mingling, observing and lingering: everyday public spaces and their implications for well-being and social relations. Health and Place, 14, 544 - 561. Available at:

http://www.sciencedirect.com/science/article/pii/S1353829207000913

Corcoran, R. and Marshall, G. (2015) Community Wellbeing: Creating pro-social spaces. London: What Works Wellbeing Available at: https://whatworkswellbeing.org/blog/community-wellbeing-creating-prosocial-places/ (accessed: 21 June 2018)

Derrett, R. (2011), 'Festivals, events and the destination', in Yoeman, I., Robertson, M., Ali-Knight, J., Drummand, S. and McMahon-Beattie, U. (eds) Festival and events management, an international arts and culture perspective. Abbingdon: Routledge Chpt 3

Dyer, L. (2016), 'Pride of the Community', Arts Council England (blog), https://www.artscouncil.org.uk/read-all-blog-posts/pride-community (accessed 21 June 2018)

Ehrenreich, B. (2007), Dancing in the Streets: A History of Collective Joy, London: Granta 
Foucault, M. (2008). 'Of other spaces (1967)', in M. Dehaene and L. De Cauter (eds.). Heterotopia and the city: Public space in a postcivil society. London: Routledge, pp.13-29

Halton NHS Commissioning Group, (2017) A cultural manifesto for wellbeing, Available at: http://www.haltonccg.nhs.uk/public-

information/Documents/A\%20Cultural\%20Manifesto\%20for\%20Wellbeing.pdf (accessed 3 February 2019)

Heller, A. and Adams, T. (2009) 'Creating healthy cities through socially sustainable placemaking', Australian Planner, 46 (2),18-21, DOI:

10.1080/07293682.2009.9995305

Holden, J. (2019), 'Escaping the Catch-22', Arts Professional. Available at: https://www.artsprofessional.co.uk/magazine/article/escaping-catch22?utm_source=Weekly-Good-Reads\&utm_medium=email\&utm_content=nid$\underline{210635 \& u t m \_c a m p a i g n=21 s t-F e b r u a r y-2019}$ (accessed 21 February 2019)

Johnson, P. (2006), 'Unravelling Foucault's Different Spaces', History of the Human Sciences, 19 (4), 75-90.

Jones, R. and Yates, G. (2013) Briefing Paper 11 - Concepts Series: The built environment and health: an evidence review, Glasgow: Glasgow Centre For Population Health, Available at: https://www.gcph.co.uk/assets/0000/4174/BP_11__Built_environment_and_health_-_updated.pdf (accessed 3 February 2019)

Koohsari, M.J., Mavoa, S., Villanueva, K., Sugiyama, T., Badland, H., Kaczynski, A.T, Owen, N. and Giles-Corti, B. (2015) 'Public open space, physical activity, urban design and public health: Concepts, methods and research agenda', Health and Place, 33, pp. 75 - 82, https://doi.org/10.1016/j.healthplace.2015.02.009. 
Laing, J. and Mair, J. (2015), 'Music festivals and social inclusion: The festival organizers' perspective', Leisure Sciences, 37 (3), pp. 252-68, https://doi.org/10.1080/01490400.2014.991009

Local Government Association (2017), People, Culture, Place: The Role of Culture in Placemaking, London: LGA,

https://www.local.gov.uk/sites/default/files/documents/12.3\%20- \%20culture \%20and\%20place_v4_1_1.pdf (accessed 1 May 2018)

Locality (2018), People Power: Findings from the Commission on the Future of Localism, London: Locality,

https://locality.org.uk/wp- content/uploads/2018/03/LOCALITY-LOCALISMREPORT-1.pdf (accessed 31 March 2018)

Marmot, M. (2010) Marmot review: fair society: healthy lives, Institute of Health London: Equity. Available at: http://www.instituteofhealthequity.org/resourcesreports/fair-society-healthy-lives-the-marmot-review/fair-society-healthy-livesfull-report-pdf.pdf (accessed 3 February 2019)

Marmot, M. (2018) The health gap: the challenge of an unequal world. London: Bloomsbury Publishing

Massey, D. (2005), For Space, London: Sage

Mulligan. M. Humphrey, K., James, P., Scanlon, C., Smith, P. and Welch, N. (2006), Creating Community: Celebrations, Arts and Wellbeing Within and Across Local Communities, Melbourne: The Globalism Institute,

https://www.creativecity.ca/database/files/library/creating_community.pdf (accessed 25 March 2019)

NHS England (2018) Putting health into place; introducing NHS England's Healthy New Towns Programme. NHS England Publications Gateway 08473 
Available at: https://www.england.nhs.uk/wp-

content/uploads/2018/09/putting-health-into-place.pdf (accessed 4 November 2018)

Russell, C. (2011) 'Pulling back from the edge: an asset-based approach to ageing well', Working with Older People, 15(3), pp. 96-106 DOI

$10.1108 / 13663661011176642$

Wilkinson, R. and Pickett, K. (2011) The spirit level: Why equality makes

societies stronger, New York: Bloomsbury Press 